\title{
COMPARISON OF EFFECTS OF BUPIVACAINE AND ROPIVACAINE IN PATIENTS UNDERGOING ELECTIVE CESAREAN SECTION
}

\author{
Subba $S^{1^{*}}$, Chhetri $A^{2}$, Bhattarai $R^{3}$
}

\begin{abstract}
Affiliation
1 Department of Anesthesiology, Critical Care and Pain Management, Nobel Medical College Teaching Hospital, Biratnagar

2 Consultant, Department of Anesthesiology and Critical Care, Neuro Cardio and Multispeciality Hospital Pvt Ltd, Biratnagar

3 Assisant Professor, Department of Anaesthesiology, Critical Care and Pain Management, Nobel Medical College Teaching Hospital, Biratnagar
\end{abstract}

\section{ARTICLE INFO}

Received : 22 November, 2019

Accepted : 25 December, 2019

Published : 31 December, 2019

(C) Authors retain copyright and grant the journal right of first publication with the work simultaneously licensed under Creative Commons Attribution License CC - BY 4.0 that allows others to share the work with an acknowledgment of the work's authorship and initial publication in this journal.

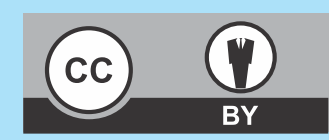

ORA 147

DOI: http://dx.doi.org/10.3126/bjhs.v4i3.27042

* Corresponding Author

Dr Sangeeta Subba

Lecturer

Department of Anesthesiology, Critical Care and Pain Management Nobel Medical College Teaching Hospital, Biratnagar

Email: sangytasubba@hotmail.com

ORCID: https://orcid.org/0000-0003-3107-8911

\section{Citation}

Subba S, Chhetri A, Bhattarai. Comparison of Effects of Bupivacaine and Ropivacaine in Patients Undergoing Elective Cesarean Section. BJHS 2019; 4 (3)10:859-863.

\section{ABSTRACT}

\section{Introduction}

Spinal anesthesia is considered a reasonable choice for cesarean section. Bupivacaine and ropivacaine have been used as intrathecal drugs alone or in combination with various opioids. Ropivacaine is considered a valid and safe alternative to bupivacaine for spinal anesthesia.

\section{Objective}

To compare the efficacy and safety of hyperbaric ropivacaine with hyperbaric bupivacaine in spinal anesthesia for elective cesarean section.

\section{Methodology}

Sixty pregnant women undergoing elective cesarean section were allocated into two groups. Group $\mathrm{R}$ received 3 $\mathrm{ml}$ of $0.5 \%$ hyperbaric ropivacaine $(2 \mathrm{ml} 0.75 \%$ plain ropivacaine mixed with $1 \mathrm{ml}$ of $25 \%$ dextrose) and Group B received $2.5 \mathrm{ml}$ of $0.5 \%$ hyperbaric bupivacaine. Both the groups were compared in terms of onset of sensory and motor block, regression of sensory and motor block, duration of analgesia and side effects.

\section{Result}

The onset of sensory block was comparable in both groups but was statistically insignificant. The onset of motor block in Bupivacaine $(7.53 \pm 1.72)$ min was faster when compared to Ropivacaine group $(14.33 \pm 6.19) \mathrm{min}$. Regression of sensory and motor block both were faster in Ropivacaine group. Duration of analgesia was longer in Bupivacaine group (131.17 \pm 32.95$)$ min than Ropivacaine group (125.33 $\pm 30.54) \mathrm{min}$.

\section{Conclusion}

Ropivacaine can be used as an alternative to Bupivacaine for spinal anesthesia in cesarean section but has a shorter duration of sensory and motor block.

\section{KEYWORDS}

Bupivacaine, cesarean section, pregnancy, ropivacaine, spinal anesthesia 


\section{INTRODUCTION}

The objective of an anesthesiologist is to make the patient free of pain, during both surgical procedure and postoperative period since the outcome of untreated pain and inadequate anesthesia can be devastating. ${ }^{1}$ Adequate analgesia enables early rehabilitation and reduces hospital stay by restoring normal functions like ventilation, coughing and mobility. ${ }^{2}$ Several options are available for intraoperative anesthesia as well as postoperative analgesia. ${ }^{3}$ Nevertheless, spinal and epidural analgesia, wherever possible using local anesthetics with or without additives are among them. They provide distinct benefits over other modalities like general anesthesia and peripheral nerve blocks. ${ }^{4}$

Bupivacaine is commonly used for spinal anesthesia during cesarean delivery. Ropivacaine is now becoming popular, since sensory nerve fibers are blocked more readily than motor fibers, and has reduced cardiac toxicity with overdose. ${ }^{5}$ Ropivacaine and Bupivacaine both belong to amino-amide group of local anesthetic drugs. Though they have same mechanism of action as other local anesthetics, there are some differences in their structural, physiochemical, pharmacokinetic and pharmacodynamic properties. ${ }^{6-8}$ Ropivacaine is enantiomerically pure (S-enantiomer), whereas, Bupivacaine is a racemic mixture of two ( $R$ and $S$ ) enantiomer of same class, structurally related to bupivacaine, but with fewerneurotoxicity and cardiac toxicity. ${ }^{9}$

Bupivacaine is widely used for cesarean section under spinal anesthesia in Nepal. Therefore this study aims to compare the safety and efficacy of bupivacaine and ropivacaine in patients undergoing elective cesarean section under spinal anesthesia. Both the drugs will be compared in terms of onset of both sensory and motor block, duration of analgesia and it's side effects like hypotension, bradycardia, nausea, vomiting and shivering.

\section{METHODOLOGY}

This Hospital based, Prospective, Comparative study was conducted in Department of Anesthesiology of Nobel Medical College Teaching Hospital, Biratnagar from May 2018 to December 2018 after taking informed consent from the patients and ethical clearance from institutional review committee.

Sample size calculation was done using the formula, $N=$ $2 \operatorname{SD}^{2}\left(Z_{12}+Z_{12}\right) / d^{2}$. A power analysis based on data from a study done by Nuray CE and Berrin G, in which the mean duration to reach maximum sensory block was measured with ropivacaine and compared with the previous data for bupivacaine. ${ }^{10}$ To detect a $3.5 \mathrm{~min}$ difference in mean duration to reach maximum sensory block between the groups for type 1 error of 0.05 and a power of $80 \%$ and a standard deviation of 4.1, a group size of 22 patients would be necessary. So we took 30 patients in each group.

A minimum of 60 cases aged 25 to 35 years, height between 150 to $165 \mathrm{~cm}$ and Weighing 50-70 kg who were planned for elective cesarean section under spinal anesthesia were included in the study. Exclusion criteria of the study consisted of Patient aged below 25 or above 35 years, patient belonging to ASA(American Society of Anesthesiologist) Physical status Grade III, IV and V, unwilling patient, known hypersensitivity to any of the study drugs, patients taking anticoagulant or antiplatelet therapy or patients with bleeding diathesis or coagulopathy, patients with spinal deformity or puncture site infection, history of any chronic disease like hypertension, diabetes mellitus, respiratory disease, psychiatric or cardiac disease, chronic history of headache and backache, any neurological or neuromuscular disease, patients in whom spinal anesthesia failed and general anesthesia was required during previous surgery, parturients having pre-eclampsia or eclampsia, any obstetric complications or signs of fetal compromise or suspected fetal malformation.

The cases were divided randomly into two equal groups by using computer generated random number list. Group $\mathrm{R}$ received $3 \mathrm{ml}$ of $0.5 \%$ hyperbaric Ropivacaine ( $2 \mathrm{ml} \mathrm{0.75 \%}$ plain ropivacaine mixed with $1 \mathrm{ml}$ of $25 \%$ dextrose) and Group B received $2.5 \mathrm{ml}$ of $0.5 \%$ hyperbaric Bupivacaine which is available commercially. Sterility was maintained by mixing autoclaved ampoules of $25 \%, 10 \mathrm{ml}$ dextrose with commercially available sterile preservative free isobaric Ropivacaine.The volume of drug in Group $\mathrm{R}$ was taken as 3 $\mathrm{ml}$ to make Ropivacaine hyperbaric and drug concentration of $0.5 \%$ since we wanted to compare between hyperbaric ropivacaine and bupivacaine. Similar volume of drug has been used in a study done by Singhal et al. ${ }^{11}$

All the patients were assessed and prepared preoperatively as per preoperative protocol of the Department of Anesthesiology of Nobel Medical College Teaching Hospital. Intravenous access was obtained with an $18 \mathrm{G}$ cannula through which all participants were pre-loaded with 20 $\mathrm{ml} / \mathrm{kg}$ of Ringer Lactate over ten minutes before inducing Spinal anesthesia. Patient either received $2.5 \mathrm{ml}$ of $0.5 \%$ hyperbaric bupivacaine or $3 \mathrm{ml}$ of $0.5 \%$ hyperbaric ropivacaine. Under all aseptic precautions the lumbar puncture was done in sitting position at the L3-4 interspace by midline approach using a 25-gauge Quincke spinal needle and study drug was given @ $0.2 \mathrm{ml} / \mathrm{sec}$ based on the groups after obtaining free flow of cerebrospinal fluid. Patients were then placed in supine position after intrathecal injection.

Sensory and motor block was assessed after the intrathecal injection at 1 and 2 minutes and the subsequently at 2 minute intervals until surgical anesthesia was achieved by an anesthesiologist who was blinded regarding the study drugs. The segmental level of sensory block to pin prick was assessed by a short beveled 27 gauge needle bilaterally along the midclavicular line. The motor block of both legs was evaluated using the modified Bromage scale $(0=$ no motor block, 1= inability to raise extended leg; able to move knees and feet, 2 = inability to raise extended leg; able to move feet, 3 = complete motor block of limb). The induction of anesthesia was considered when at least the $T_{6}$ dermatome was anaesthetized. The time of onset of sensory (loss of pin prick sensation) at $\mathrm{T}_{4}$ dermatome and motor block (complete motor block) was noted. Hemodynamic 
parameters like maternal heart rate, electrocardiogram (ECG), blood pressure and oxygen saturation $\left(\mathrm{SpO}_{2}\right)$ were monitored. The values were documented before the induction, every 2 minutes during the first 10 minutes after spinal block, then every 5 minutes during the first hour and then every 10 minutes until the patient is transferred to the recovery room. Oxygen at a rate of $4 \mathrm{~L} / \mathrm{min}$ was given via face mask.

Fall in blood pressure and heart rate below $20 \%$ of the baseline values were defined as hypotension and bradycardia. Intravenous boluses of mephentermine $6 \mathrm{mg}$ initially and which added up to a maximum of $30 \mathrm{mg}$ if required, was given to treat hypotension and intravenous atropine was given to treat bradycardia. Intravenous ondansetron $4 \mathrm{mg}$ was given to treat nausea and vomiting.

Patients who requested to sleep received intravenous Midazolam $2 \mathrm{mg}$ after the delivery of the baby. Intravenous Fentanyl $50 \mu \mathrm{g}$ was administered for pain or discomfort during surgery.

The duration of surgery was noted after the completion of surgery, and the patient shifted to the postoperative ward. Regression of sensory and motor blockade was examined by the researcher. The residual sensory blockade was examined every $15 \mathrm{~min}$ and its wearing off time was noted (when sensation to pin prick regressed to T10). Residual motor blockade was examined every $15 \mathrm{~min}$ and its wearing off time was noted (when patient start to lift leg against gravity).Pain was assessed using Numerical Rating Scale (NRS). Time for first request for postoperative analgesic (duration of analgesia) was noted and Injection Tramadol 50 mg was given when the NRS score was 5 or more. All patients were assessed for possible adverse effects due to hemodynamic changes and treated accordingly. Data was collected and recorded as per working proforma. Data analysis was done by statistical package for the social sciences(SPSS) version 16 using independent t test for numerical data. A $p$ value 0.05 was considered to be statistically significant.

\section{RESULTS}

A total of 60 eligible participants, enrolled in the study were assigned into two study groups. The groups were comparable in terms of age, weight and duration of surgery (Table 1 ).

Table 1: Comparison of demographic profile between
two group
\begin{tabular}{|l|c|c|c|}
\hline & $\begin{array}{l}\text { Bupivacaine } \\
\text { Group(n=30) }\end{array}$ & $\begin{array}{c}\text { Ropivacaine } \\
\text { Group(n=30) }\end{array}$ & p-value \\
\hline Age(years) & $24.2 \pm 3.99$ & $26.07 \pm 4.56$ & 0.097 \\
\hline Weight(kg) & $66.7 \pm 6.23$ & $66.03 \pm 7.77$ & 0.715 \\
\hline $\begin{array}{l}\text { Duration of } \\
\text { surgery (min) }\end{array}$ & $31.17 \pm 9.44$ & $30.17 \pm 12.07$ & 0.722 \\
\hline
\end{tabular}

The characteristics of block between two groups is shown in table 2. The onset of sensory block were comparable in both groups. There was statistically significant difference in onset of motor block in Bupivacaine(7.53 \pm 1.72 ) min and Ropivacaine group (14.33 \pm 6.19$)$ min respectively. Regression of sensory and motor block both were faster in Ropivacaine group. Duration of analgesia was longer in Bupivacaine group $(131.17 \pm 32.95)$ than Ropivacaine group $(125.33 \pm 30.54)$.

Table 2: Comparison of characteristic of block between
two groups
\begin{tabular}{|l|l|l|l|}
\hline & $\begin{array}{l}\text { Bupivacaine } \\
\text { Group (n=30) }\end{array}$ & $\begin{array}{l}\text { Ropivacaine } \\
\text { Group (n=30) }\end{array}$ & p-value \\
\hline Onset sensory(min) & $4.87 \pm 1.46$ & $4.87 \pm 1.72$ & 1.000 \\
\hline Onset motor(min) & $7.53 \pm 1.72$ & $14.33 \pm 6.19$ & 0.000 \\
\hline Regression Sensory(min) & $140.5 \pm 41.03$ & $131.5 \pm 38.71$ & 0.386 \\
\hline Regression motor(min) & $171.33 \pm 38.73$ & $98.5 \pm 34.47$ & 0.000 \\
\hline Duration of analgesia(min) & $131.17 \pm 32.95$ & $125.33 \pm 30.54$ & 0.480 \\
\hline
\end{tabular}

The table 3 compares the various side effects and requirement of rescue analgesia between two groups. The incidence of hypotension and bradycardia is similar in both groups but three patients in Bupivacaine group had shivering and two patients require rescue analgesia.

Table 3: Comparison of side effects between two groups
\begin{tabular}{|l|c|c|}
\hline \multicolumn{1}{|c|}{ Side effects } & $\begin{array}{c}\text { Bupivacaine } \\
\text { Group (n=30) }\end{array}$ & $\begin{array}{c}\text { Ropivacaine } \\
\text { Group (n=30) }\end{array}$ \\
\hline Hypotension & 15 & 16 \\
\hline Bradycardia & 1 & 1 \\
\hline Shivering & 3 & 1 \\
\hline Vomiting & 0 & 1 \\
\hline Rescue analgesia & 2 & 0 \\
\hline
\end{tabular}

The changes in heart rate( $\mathrm{HR})$, oxygen saturation $\left(\mathrm{SPO}_{2}\right)$ and mean arterial pressure(MAP) over time is shown in figure 1 , figure 2 and figure 3 respectively.

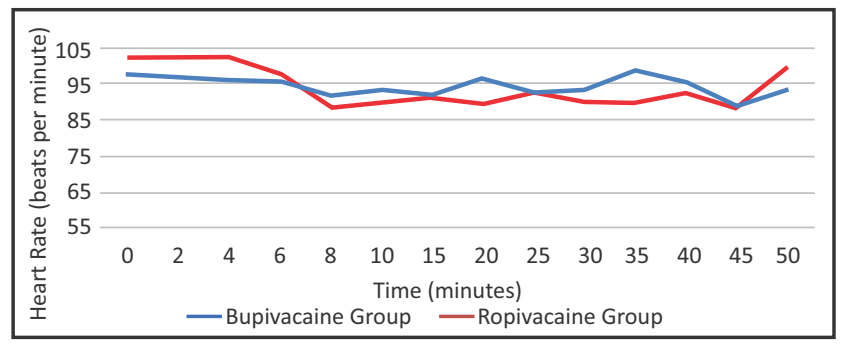

Figure 1: Heart rate trend in two groups.

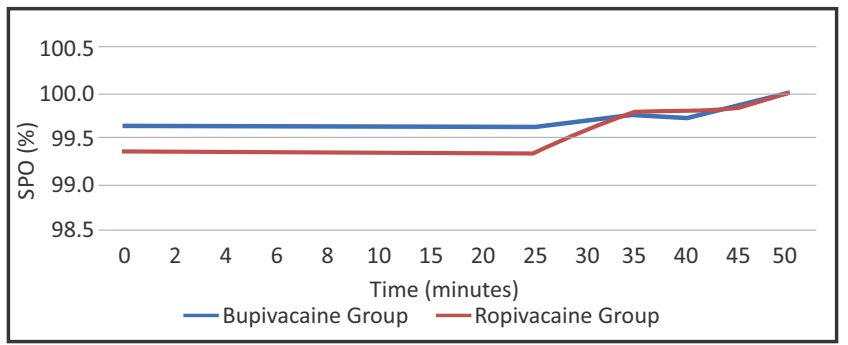

Figure 2: $\mathrm{SPO}_{2}$ trend in two groups

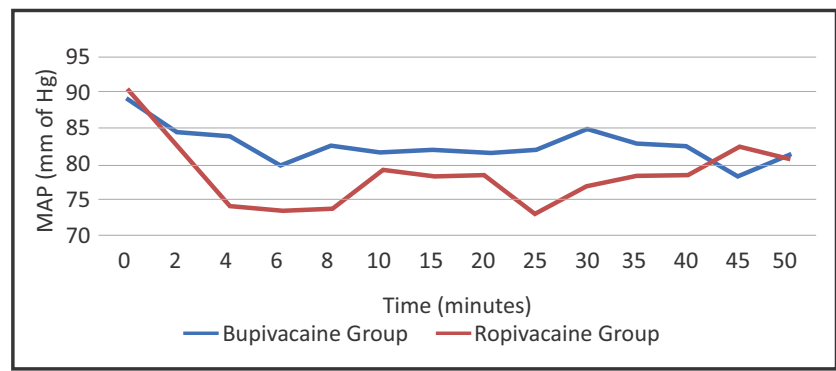

Figure 3: MAP trend in two groups. 


\section{DISCUSSION}

This study demonstrated that $0.5 \%$ hyperbaric ropivacaine can be used as an alternative to $0.5 \%$ hyperbaric bupivacaine in spinal anesthesia for elective cesarean delivery but with shorter duration of sensory and motor block.

In our study we found out that there was no statistical difference in onset of sensory block between two groups. The onset of sensory block in both Ropivacaine group and Bupivacaine group was similar (4.87 min) in our study. This finding is in contrary to the finding of the study done by Singh et al where the onset of sensory block is delayed in Ropivacaine group. ${ }^{12}$ This may be attributable to the fact that we have used $0.5 \%$ hyperbaric Ropivacaine instead of $0.75 \%$ isobaric Ropivacaine used by Singh et al. Addition of glucose would increase the density of drug resulting in a more even distribution of the local anaesthetic, gravity presumably encouraging spread of the bolus of drug 'down' the slopes of the lumbar curve when the patient is placed supine after injection. ${ }^{13}$ It is now a well-known fact that, hyperbaric solutions when compared with plain local anaesthetic solutions results not only in a more predictable cephalad spread, but also prolongs the duration of the clinically useful block (given by duration at the T10 dermatome), and leads to a more rapid regression of sensory block and recovery from motor block. ${ }^{14,15}$

The onset of motor block was faster in Bupivacaine group in comparison to Ropivacaine group. The regression of sensory and motor block was faster in Ropivacaine group in comparison to Bupivacaine group. The regression of sensory block was quicker than regression of motor block in Bupivacaine group whereas in Ropivacaine group the motor block regressed faster than sensory block. The duration of analgesia lasted slightly longer in Bupivacaine group. These results confirm that spinal bupivacaine is more potent than ropivacaine in terms of onset of motor block, regression of sensory and motor block and duration of analgesia. This may be attributable to the fact that ropivacaine is less lipid soluble which causes the drug to penetrate the large myelinated A fibers more gradually than the more lipidsoluble bupivacaine. ${ }^{16}$ Similar findings were found in studies done by Singh et $\mathrm{al}^{12}$, Chung et $\mathrm{al}^{17}$, Danelli et $\mathrm{al}^{18}$, Eryilmaz et al $^{10}$, Bhat al ${ }^{19}$, Chari et al $^{20}$ and Ingale et al. ${ }^{21}$

The incidence of side effects like hypotension and bradycardia

\section{REFERENCES}

1. Apfelbaum JL, Chen C, Mehta SS, Gan TJ. Postoperative pain experience: results from a national survey suggest postoperative pain continues to be undermanaged. AnesthAnalg. 2003 Aug; 97(2): 534-40. PMID: 12873949

2. Vickers A, Bali S, Baxter A, et al. Consensus statement on the anticipation and prevention of acute postoperative pain: multidisciplinary RADAR approach. Curr Med Res Opin. 2009 oct; 25: 2557-69. DOI: 10.1185/03007990903281059

3. Harsoor S. Emerging concepts in post-operative pain management. Indian J Anaesth. 2011; 55: 101-3. DOI: 10.4103/0019-5049.79872 were comparable in both groups. Shivering was observed more in Bupivacaine group and one patient had vomiting in Ropivacaine group. Rescue analgesia was required in Bupivacaine group. Similar findings were also seen in study done by Chung et $\mathrm{al}^{17}$ and Srivastava et $\mathrm{al}^{22}$.

Although our study shows that Bupivacaine is more potent than Ropivacaine when used in spinal anesthesia, Ropivacaine may be appropriate for short procedures where a rapid return of ambulatory function is required, and its recovery profile could confer a distinct clinical benefit. Early recovery from anesthesia might as well increase the patient's satisfaction.

\section{CONCLUSION}

Ropivacaine can be used as an alternative to Bupivacaine in patients undergoing cesarean section under spinal anesthesia but with shorter duration of sensory and motor block.

\section{RECOMMENDATIONS}

This study compared the effect of Ropivacaine and Bupivacaine in patients undergoing elective cesarean section only. Further studies should be done in patients undergoing lower abdominal and lower limb surgeries. The minimum and effective dose of Ropivacaine required for cesarean section has not been explored that much. Therefore such studied can be conducted in future.

\section{LIMITATION OF THE STUDY}

This study has been conducted in only one hospital and the study population were pregnant women undergoing cesarean section. Therefore the result may not be representative of general population. The comparison of height of the patients between two groups were not done in this study. The volume of drug in both the groups were different. Both the factors might have impact on the result of the study.

\section{ACKNOWLEDGEMENT}

I would like to thank all the patients who participated in this study. Thankful to my collegues, seniors and juniors without whom this study would not have been possible.

\section{CONFLICT OF INTEREST}

None declared

4. Choi PT, Bhandari M, Scott J, Douketis J. Epidural analgesia for pain relief following hip or knee replacement. Cochrane database 2003 July.PMID:12917945

5. Malinovsky JM, Charles F, Kick O, Lepage JY, Malinge M, Cozian A, et al. Intrathecal anesthesia: ropivacaine versus bupivacaine. AnesthAnalg. 2000 Dec; 91(6): 1457-60. PMID: 11094000

6. McDonnald SB , Liu SS, Kopacz DJ, Stephenson CA . Hyperbaric spinal ropivacaine: a comparison to bupivacaine in volunteers Anesthesiology. 1999 Apr;90(4):971-7. PMID: 10201665

7. Alley EA, Kopacz DJ, McDonald SB, Liu SS. Hyperbaric spinal bupivacaine: a comparison to racemic bupivacaine in volunteers. AnesthAnalg. 2002 Jan;94(1):188-93.PMID: 11772826 
8. Cox GR, Faccenda KA, Gilhpooly C, Bannister J, Scott NB, Morrisson LMM. Extradural S (-)-Bupivacaine: comparison with racemic RSBupivacaine. Br J Anaesth. 1998 Mar;80(3);289-93.https:// doi.org/10.1093/bja/80.3.289

9. Abouleish EJ, Elias M and Nelson C. Ropivacaine induced seizure after extradural anesthesia. Br J Anaesth. 1998 June;80(6):843-4. PMID: 9771320

10. Eryilmaz NC, Günaydin B.A comparison of the effects of intrathecal ropivacaine and bupivacaine during cesarean section.Turk J Med Sci. 2011;41(2): 219-26. DOI:10.3906/sag-1008-994

11. Singhal RK, Vyas CK, A comparative study of hyperbaric Ropivacaine with Bupivacaine as spinal anaesthesia. Journal of Dental and Medical Sciences. 2016;15(1):1-5. DOI: 10.9790/0853-15120105

12. Singh S, Singh VP,Jain M,Gupta K,Rastogi B,Abrol S.Intrathecal $0.75 \%$ Isobaric Ropivacaine Versus $0.5 \%$ Heavy Bupivacaine for Elective Cesarean Delivery: A Randomized Controlled Trial. J PAK MED STUD.2012 Apr-Jun;2(2):75-80

13. Hocking G, Wildsmith JAW. Intrathecal drug spread. Br J Anaesth. 2004; 93: 568-78.https://doi.org/10.1093/bja/aeh204

14. Fettes PDW, Hocking G, Peterson MK, Luck JF, Wildsmith JAW. Comparison of plain and hyperbaric solutions of ropivacaine for spinal anaesthesia. Br J Anaesth 2005; 94: 107-11.doi:10.1093/ bja/aei008

15. Kallio H, Snall E-VT, Tuomas CA, Rosenberg PH. Comparison of hyperbaric and plain ropivacaine $15 \mathrm{mg}$ in spinal anaesthesia for lower limb surgery. Br J Anaesth 2004; 93: 664-9.PMID:15347608

16. Rosenberg PH, Kytta J, Alila A. Absorption of bupivacaine, etidocaine, lignocaine and ropivacaine into $\mathrm{N}$-heptane, rat sciatic nerve and human extradural and subcutaneous fat. $\mathrm{Br}$ J Anaesth. $1986 \mathrm{Mar}$; 58(3): 310-4.PMID: 3947493
17. Chung, Jong C, Choi, Ron S, Yeo, Hwan K, et.al. Hyperbaric Spinal Ropivacaine for Cesarean Delivery: A Comparison to Hyperbaric Bupivacaine. Anesthesia \& Analgesia. 2001 july;93(1):157-61.DOI: 10.1097/00000539-200107000-0003116.

18. Danelli G, Fanelli G, Berti M, Cornini A, Lacava L, Nuzzi M, et. Al. Spinal Ropivacaine or Bupivacaine for Cesarean Delivery: A Prospective, Randomized, Double- Blind Comparison. Regional Anesthesia and Pain Medicine. 2004 May-Jun; 29(3):221-6.DOI:10.1016/j.rapm. 2004.02.003

19. Bhat SN, Himaldev, Upadya M. Comparision of efficacy and safety of ropivacaine with bupivacaine for intrathecal anesthesia for lower abdominal and lower limb surgeries. Anesth Essays Res. $2013 \mathrm{sep}-\mathrm{dec}$; 7(3): 381-5.PMID: 25885988

20. Chari VRR, Goyal A, Sengar PK, Wani N. Comparison between intrathecal isobaric ropivacaine $0.75 \%$ with hyperbaric bupivacaine 0.5\%: A double blind randomized controlled study. Anaesth Pain \& Intensive Care. 2013;17(3):261-6.

21. Ingale L, Dalal S, Ingale S, Tirpude NG,Tarkase ASand Gedam MC. A comparative study of $0.5 \%$ hyperbaric Ropivacaine versus $0.5 \%$ hyperbaric Bupivacaine for spinal anaesthesia. International Journal of Biomedical and Advance Research. 2016;7(6): 286-291. DOI: 10.7439/ijbar

22. Srivastava U,Joshi K, Gupta A, Dwivedi Y, Anand Y, Kannaujia A, et. al. Comparison Of Intrathecal Hyperbaric Ropivacaine And Bupivacaine For Caesarean Delivery. The Internet Journal of Anesthesiology. 2012;30(4):1-6. 